\title{
Mentoring when Librarians Have Faculty Status
}

Phillipa Brown, Vincent Novara, Jane Williams

University of Maryland Libraries, USA 


\section{ABSTRACT}

Numerous academic libraries participate in their campuses' systems for faculty status for librarians, in separate tracks or identical tracks as those for teaching faculty. In either case, a practice is to encourage or require mentoring for librarians without tenure or permanent status. This chapter will cover the special challenges and benefits of mentoring and faculty status, the need for mentoring, and processes for best practices to make mentoring meaningful for all involved. The chapter will draw on the authors' experiences, an environmental scan, a survey of selected institutional practice where librarians have faculty status, and published research and related literature. It will also feature mentoring programs developed by various institutions, including the University of Maryland Libraries. 
KEYWORDS Academic libraries, faculty librarians, library faculty, mentoring

\section{INTRODUCTION}

This chapter is written from the vantage points of three individuals with faculty status at the University of Maryland Libraries, two of whom do not have permanent status and one who does. One is a curator, one is a human resources professional, and the third is a librarian by profession. However, despite distinctive backgrounds, all are or have been subject to the same requirements for promotion and permanent status (or tenure, used interchangeably). The chapter thus blends those backgrounds and experiences as it explores the topic of mentoring for academic librarians as an important population among information professionals.

The chapter posits that librarians and others with library faculty status need a targeted mentoring program that addresses librarianship, service and scholarship. This is especially needed for those without permanent status or tenure, to help those individuals meet requirements that do not pertain in institutions where librarians and other professional staff do not have faculty status. The chapter also posits that these special, standardized mentoring programs in an institution, targeted toward attaining tenure, are effective. This thesis is based on qualitative data. The chapter's observations, recommendations and conclusions are grounded in the authors' experiences at the University of Maryland Libraries (UML) and/or are confirmed in the literature and other institutions' experiences. The authors believe that standardized, formal mentoring programs provide value to the individual and the organization, especially where librarians have faculty status. The chapter also identifies the need for more systematic data collection and analysis on these special mentoring programs and their efficacy, not just for the individuals gaining promotion and tenure, but in retention at the employing library too.

The purposes of the chapter are to set forth various aspects of mentoring programs for three audiences:

1. Key factors essential to successful mentoring programs in academic libraries, for those looking to establish or improve mentoring programs;

2. Essential elements as they relate to requirements when librarians and other professionals working in academic libraries have faculty status, to guide potential mentees and mentors; and

3. Examples and guides for successful programs, for program coordinators as well as mentors and mentees.

\section{BACKGROUND}

Mentoring in the workplace is not new. It has been prevalent in society for centuries and has woven its way into the work environment. Mentor refers to a trusted friend, counselor, or teacher. The word dates to Homer's Odyssey, in which Odysseus planned to leave for the Trojan Wars and asked his friend, Mentor, to watch over and guide his son Telemachus during his absence. Though the concept of mentoring was created through Homer, it gained popularity during the $15^{\text {th }}$ century in Francois Fenelon's literary work Les Aventures de Telemaque. It is believed that the addition of mentor to the Oxford English Dictionary as a common noun in 1750 was the result of this popular work (Murray, 2001). 
Webster’s New Collegiate Dictionary defines mentor by referencing Odysseus’ friend named Mentor, while also describing a mentor as a trusted counselor or guide. Eastern Illinois University defines faculty mentoring as “.... mentoring relationship that is a developmental process that involves mutual caring, sharing, and helping” (2009). The University of Iowa describes the mentor as "someone with greater experience (mentor) that offers support and guidance, and advice to facilitate the learning and development of someone with lesser experience, that is, the mentee” (2008). Washington State University states that "mentoring is a process through which a new, untenured faculty member receives guidance and support for successful career enhancement and professional advancement” (2009). The authors' literature review revealed three recurring characteristics: foremost, the mentor is seasoned and more experienced in his or her field of expertise than the mentee; the mentor is generally the lead person in the relationship and initially leads the direction; third, the mentor is generally older than the mentee.

At UML, mentoring means that there is a formal or informal relationship that exists between two individuals. The lead person is usually the more experienced, in keeping with the trends noted above. The relationship exists primarily for the experienced individual to provide guidance, support, encouragement, collaboration, and networking opportunities that assist the mentee in satisfying tenure requirements. The UM College of Chemical and Life Sciences has developed a Guide for Faculty Mentors (and Mentees), which describes faculty mentoring as providing

professional socialization including entry into a disciplinary network. Ideally, the mentor also becomes a sounding board and supporter, who teaches the 'tricks of the trade' and survival strategies to the mentee. Most often the mentor serves to help the mentee become successful at his/her academic institution. It is also possible that the mentor will be able to serve as a guide and resource in dealing with the broader scholarly and academic community, both nationally and internationally. (Popper, 2007, p.3).

Whether in the academy, the private or public sectors, mentoring remains a popular and useful tool in the workplace. Since there are so many benefits to mentoring, its migration from the social culture into the subculture of work is no surprise. Mentoring can be a critical means to an end as it serves to develop talent, plan for succession of leadership, identify employee needs and resources, and create opportunities for information exchange. At the University of Maryland, mentoring is strongly encouraged and supported among both the teaching and library faculty. The UML have a history of interest and support in developing and maintaining a strong and successful faculty mentoring program. More recently, UML reviewed and updated their existing Faculty Mentoring Program and took considerable time and effort to streamline the process and to remove identifiable barriers, in order to encourage participation of the library faculty. All UML faculty without permanent status are now part of the Faculty Mentoring Program.

\section{CHALLENGES, BENEFITS, AND PRACTICES OF MENTORING PROGRAMS}

\section{Challenges}

This section first highlights some of the challenges of mentoring within an organization generally, and then examines challenges in the context of an academic library where librarians have faculty status.

\section{Organizational Issues}

Organizational environments that proactively support a mentoring program provide the greatest opportunity for success of the program and its participants. Whether the organization is a business setting or in higher education, challenges for mentoring programs may arise in various forms of resistance. 
Benefits can be derived from facing and dealing with challenges associated with a lack of vision and mission, failure to educate members of the academy about the program, inadequate implementation due to financial or other constraints, achieving the correct match between mentor and the mentee, and absence of an assessment tool.

Organizational vision and mission, together with education, help to promote the mentoring program and to establish the need to mentor as part of an organization's internal value system. Providing the time, the training, and the financial support necessary for implementation further demonstrates the organization's advocacy of professional development through mentoring. Additionally, a mentoring program should pay attention to what constitutes a compatible match based on the specific skills, common interests, and abilities of the mentor and the mentee. Finally, an organization needs to allow for exploration of other matches should the original pairing not be successful.

As the organization works to resolve these issues, the challenges and priorities will shift. These shifts will be influenced by a rapidly changing technology, succession plans, and maintenance of institutional knowledge. However, even where programs succeed, the organization should continue to assess and flexibly modify the mentoring program when appropriate. The assessment should integrate a level of accountability that examines both institutional efforts toward supporting mentoring and individual results.

The three areas that tend to be constant challenges are financial support, assessment, and revision. While their priority order may change, they will remain challenges, and they will continue to serve as motivators to ensure the mentoring effort remains up-to-date and innovative.

\section{Challenges and Benefits of Faculty Status with Mentoring for Librarians}

Librarians can be challenged by their academic preparation, philosophical outlook or performance expectations to understand, adapt to, subscribe to, or meet the customary criteria associated with teaching faculty. Developing a balanced, full portfolio in teaching (librarianship), service, and scholarship can appear daunting to individuals new to the professional ranks, and the efforts to prepare a successful dossier may affect an institution's success in recruiting, retaining, and developing librarians.

\section{Librarianship}

The portfolio for librarianship may include reference or information service, bibliographic instruction, collection development, the management and maintenance of said collections and/or staff, the creation of guides, or otherwise contributing to the collective work of the larger organization. These duties constitute a full-time position that leaves little time for additional requirements of service or scholarship and creativity.

The benefits of faculty status for librarians are frequently equated to those for teaching faculty: encouragement to pursue research and creative endeavors, continuing professional and intellectual development, self-governance, and the personal reward and satisfaction that come from teaching or instruction. An additional benefit (or a concern) is the relief from duties that support staff can perform. Mitchell and Morton (1992) say it best: "It is a commitment to a transcendent academic culture, to an intellectual community, and to the pursuit of inquiry. Thus, most faculty perform as they do not because they are made to, but because they want to and need to, for that is what they are about” (p. 387). Despite such benefits, challenges persist.

For librarians, the challenges of meeting the expectations of faculty are significant. As stated earlier, meeting the demands of librarianship requires a full-time commitment. It is an ever-evolving field that endeavors to match the developments in higher education (Field, 2001). This particular challenge 
requires periodic re-training and active participation in professional organizations to keep abreast of trends and advances in technology. An additional challenge is the limited resources allocated to some academic libraries. Budgets ebb and flow, and can leave librarians and their employing institutions illequipped to meet professional development needs. A strong mentoring program can provide the support institutions need to retain and develop their librarians when faced with such challenges (Munde, 2000).

An experienced and well-matched mentor can advise his or her mentee on which training opportunities to pursue. Te mentor can also help determine which professional organizations are best suited to the librarian's present duties and long-term career goals. With those factors identified, together they can

1. Implement a plan to best utilize any available professional development or travel funding,

2. Determine strategies for pursuing support from other sources of funds, such as grants or scholarships, or

3. Decide when to turn to personal funds.

A mentor must remain aware of the performance demands of the librarian's appointment. One consideration is the time the appointment provides for career development towards promotion and tenure. Another consideration is the possibility of success, given the parameters of performance evaluation, since the expectations and needs of the supervisor must be met as well. If the mentee feels that performance expectations are unrealistic, a mentor may need to advise the mentee on negotiating those expectations with his or her supervisor.

\section{Service}

The service criterion for faculty librarians creates both opportunities and challenges. Faculty librarians are commonly encouraged to serve locally, at the institutional level, and nationally, in professional organizations. A service portfolio can include membership in professional organizations that are directly related to the appointment duties or the subject specialization; holding elected offices or serving on committees for such organizations; membership on library system committees; and membership on campus or university system committees. Even with such a variety of opportunities available, librarians face obstacles to service.

A significant challenge is time, as identified by Byrne (2003). With a full-time position, the librarian must designate time to attend meetings and conferences, read or participate in online discussions, and read professional journals and newsletters. Furthermore, librarians new to the profession frequently cannot clearly determine which professional organizations are right for their careers. In these instances, mentees should consult about organizations that can provide the most benefits. Next, the librarian is faced with the challenge of finding engaging and worthwhile service opportunities within a chosen organization. Mentors can make introductions and advise on service opportunities that yield the highest return for the time invested (Field, 2001). These service opportunities are more easily met when there is institutional support for costs such as conference fees and travel expenses. Some institutions such as UML provide professional development support, which can cover the travel expenses and other fees, though membership dues are typically the responsibility of the librarian. With or without support, however, the mentor can help the mentee prioritize which conferences to attend and when.

For institutional service, different challenges exist. Certain service activities are part of the job, such as serving on a committee with peers working on similar tasks (e.g., collection management committees). Others fall into the more traditional category of service. The supervisor and the mentor can help distinguish between the two types of service. A common challenge for new librarians is finding available opportunities for service in the library system while they develop their networks. Here again is an excellent opportunity for the mentor to make introductions on behalf of the mentee and to expand the 
mentee's network. Furthermore, the mentor can help guide the mentee on allotting the time for service, consistent with performance requirements outlined by the supervisor.

\section{Scholarly and Creative Activity}

The scholarship and creativity portfolio for librarians can include various components, depending on the policies of the institution. The most common forms of scholarship and creativity are articles in peer-reviewed journals, invited and juried presentations at professional conferences, or books or book chapters. Exhibitions and displays are frequently considered scholarship for faculty librarians; for curators, they are commonly viewed as part of the job (Bowen \& Roberts, 1993).

Again, time is a significant challenge. Scholarly pursuits require considerable effort by the faculty librarian. Mitchell and Morton administered a 1982-1991 survey of academic library literature showing that "research-and-publication activity is not a central part of the performance expectations of many academic libraries” (p. 385). Scholarship is another area where the mentor can advise. Also, not all scholarly pursuits are successful: articles get rejected; it is hard to find the right publication for a research topic; and invitations to present at conferences are, at least initially, difficult to attract. An ideal mentor is an active scholar who has experienced and met these challenges.

There are instances where it is difficult to distinguish between what is scholarship or librarianship - as is the case with the guides created by librarians or the aforementioned exhibitions for curators with faculty status. The mentor and supervisor must help resolve the challenges in this area. The institution's Appointment, Promotion, and Tenure (APT) Committee may also be consulted to ensure that the librarian is building the best portfolio to achieve advancement.

Given that there are only so many opportunities to publish, newer librarians need their senior colleagues to help provide opportunities or to offer collaborative projects. Mentors can help determine which avenues to pursue and introduce editors or potential co-authors. Mentees cannot expect or depend on their mentors to co-author or create the opportunities for scholarship and creativity. However, if coauthorship or co-presentation opportunities develop naturally and are mutually beneficial, a successful collaboration can both produce new scholarship and strengthen the mentoring relationship.

\section{Benefits of Mentoring}

The challenges depicted above populate the main components of the faculty librarian's career. As stated, the presence of mentoring can assist with the oscillations of each. Yet, there are additional benefits for all involved: the mentee, mentor, and the institution.

Munde observes that mentees can benefit by receiving higher salaries, experiencing greater success for promotion, and enjoying satisfaction with both their career and institution. Zellers et al. (2008), through their evaluation of studies for mentoring programs for instructional faculty at academic institutions, identified that these benefits are consistent. They also found accelerated leadership development on the part of mentees - which does not necessarily equate to promotion - and an increased motivation on the part of mentees to mentor others later on.

In a healthy, prosperous mentoring relationship, the mentor will also experience worthwhile benefits. Newer faculty librarians who are recent graduates of library or information schools will usually have a better understanding of emerging trends in the profession that they can share (Syma and Henry, 2009). The mentor may experience a sense of satisfaction of contributing to the success of another and a heightened sense of purpose. The mentor will also have earned the loyalty and support of the mentee as a byproduct of the process (Munde). Further still, it is likely that the mentor's value to the organization increases by contributing to the welfare of the institution by serving in the mentoring capacity. 
Benefits to the institution include easier socialization and communication for new hires, increased productivity, and the retention of valued employees (Munde). Zellers et al. also indicate that, with a supported mentoring program, the institution experiences greater organizational stability, preservation of institutional memory, and improved leadership and succession planning. With such results, it is clearly in the best interest of the institutions to encourage and nurture a culture of mentoring.

Many librarians welcome the full scope of the requirements of faculty status and meet them fully. When that match happens, the librarians, the library users and the institution are all enriched. Yet, this type of success is unlikely without the support of a committed and experienced mentor and a thriving mentoring program with full institutional support.

\section{MENTORING PRACTICES AMONG SELECTED INSTITUTIONS}

Mentoring programs vary from institution to institution, but many share a common factor: the development and support of tenure-track faculty librarians towards achieving tenure. These programs in particular need to meet the human resources requirements of the institution while providing a nurturing framework that demonstrates an investment into the professional welfare of the faculty.

Mentoring programs can be voluntary or mandatory. Both variations can be formally structured, with reporting, assessment mechanisms, etc., but mandatory programs are more likely to be formally structured. Field (2001) compares formal and informal programs and describes the benefits of each. As a rule, a mentor is an experienced librarian with tenure or permanent status (Sorcinelli, 2000). It is inadvisable that the supervisor serves as the formal mentor, as that may create conflict of interest (Byrne, 2003). That said, the supervisor and mentor must agree on if and how they will communicate and do so with the mentee's knowledge. This transparency helps to preserve a respectful rapport between the mentee and his or her supervisor and mentor.

The successful faculty librarian may have many people in his or her life who serve in mentoring capacities. These informal mentoring relationships develop naturally and can include former professors, associates from professional organizations, former supervisors, current colleagues, etc. While these types of mentors do contribute to the faculty member's professional growth, they may do so without full knowledge of the exact APT requirements at the mentee's institution. Relying on this kind of informal mentoring can place the mentee at a disadvantage. Marginalization of female or minority faculty members is common in many fields within academia, and places an additional barrier to developing informal mentoring relationships independent of a program (Zellers et al., 2008). Furthermore, a recent assessment of the revitalization of Kansas State University Libraries' mentoring program makes a strong case for formalized mentoring that supports the APT process. The authors found that an informal program can lead to "a patchwork of input of varying effectiveness," which does not meet the needs of new employees, nor does it provide necessary information in a "coordinated, ongoing process" (Farmer, Stockham, \& Trussell, 2009, p.8).

A formal mentoring program places accountability on the institution to ensure that its faculty librarians are operating in a system where achieving tenure is a reality. For such a program to succeed, it must account for many variables, including the profile of the mentor, the role of the supervisor, how mentors are appointed and matched to their mentees, and the use of tracking or evaluative mechanisms. Still, there are noticeable differences from program to program that merit examination. The following programs evaluated here were selected based on both their membership in the Association of Research Libraries and the availability of information on their mentoring programs. The colleges and universities libraries include the State University of New York (SUNY)-Albany, the University of Illinois at Chicago (UIC), Colorado State University, the University of Delaware, Louisiana State University (LSU), the 
University of Maryland (UML), Oklahoma State University, Rutgers University, the University of Tennessee-Chattanooga, and the University of Wisconsin-Madison.

Little quantitative data exist that support these programs' success as they pertain to promotion, tenure, and retention. It is not difficult to find information on the mechanics and policies for these mentoring programs, and therefore make recommendations on implementing such a program. It is the statistical context that is lacking. LSU, Rutgers, and SUNY-Albany report anecdotally that promotion rates have increased following the adoption of a formal mentoring program, but that retention was not a prior issue (Blessinger, K., personal communication, April 24, 2009; Troy, S. personal communication, April 24, 2009; Brustman, M. personal communication, April 20, 2009). UML's current, formal program is too nascent to determine its effects on promotion, tenure, and retention. That said, prior to instituting a program, UML experienced significant issues with retaining faculty librarians without tenure, and there were a few instances where candidates did not attain tenure. Exit interview data at UML revealed that some departing pre-tenure faculty pointed to the ambiguous expectations for faculty status at the University. Yet, Kuyper-Rushing, when reporting on instituting a mentoring program at LSU, states that it is difficult to measure the success of mentoring on promotion, tenure, and retention, and that "a successful tenure decision cannot be credited to a single event or program” (2001, p.445). New research could help address this absence of data.

Even in a broader examination of mentoring programs in other academic fields, much of the data are anecdotal and overwhelmingly focused on the positive aspects of mentoring programs (Zellers et al.). Zellers et al. were only able to determine seven studies on faculty mentoring programs that utilized any form of scientific method. The results of the studies vary, but four of which indicated that mentoring has improved both retention and attaining tenure. In select cases, job satisfaction improved as well. More data for both instructional and library faculty are needed for any true comparative analysis. The anecdotal evidence for faculty librarians does suggest a possible intersection with the evidence of success for their instructional peers.

\section{Mentor qualifications}

One common factor at five of the ten institutions examined here (SUNY-Albany, Oklahoma State University, Rutgers, LSU, and UML) is the tenure status of mentors. The ideal mentor is not only tenured, but has navigated the institution's process or has served on a tenure review committee for other candidates at the institution (Wittkopf, 1998). The reason for this status is obvious: the mentor knows the system and can therefore advise based on genuine and relevant experience. At Colorado State and Rutgers, the status of the mentor is not specified and is based primarily on the interest of the individual to serve as a mentor. Only the University of Tennessee-Chattanooga allows any librarian to serve as a mentor, because of the lack of available library faculty (Carter, Griffey, \& Prince, 2006).

Another factor shared by five of the ten institutions is the role of the supervisor vis-à-vis mentoring programs. For teaching or research faculty, the department chair is typically not encouraged to serve as the formal mentor (Zellers et al.). The same is recommended for library faculty. As stated earlier, placing the supervisor in a mentoring role may constitute a conflict of interest. The supervisor primarily operates with the interest of the library or unit, not the individual, at the front of his or her mind. This perspective may not best suit the mentee's developmental needs, but it does not prevent the supervisor from offering informal mentoring and guidance to his or her employees. That said, of the ten institutions examined, Oklahoma State, Rutgers, UIC, LSU, and UML specify in their guidelines that the supervisor cannot serve as the mentor; this caveat is implied in the documentation for Wisconsin and UTChattanooga. Only Colorado State University views the supervisor as the ideal or natural mentor. As Wittkopf notes in Mentoring Programs in ARL Libraries (ARL SPEC Kit 239, 1998), supervisors for the majority of the ten institutions do not appoint the mentors for their employees. 


\section{Appointing the Mentor}

There are several options for pairing a mentor with a mentee. At nine of the ten institutions, a committee, a committee member, or a human resources employee appoints mentors. (The exception is Rutgers, where the university librarian appoints mentors.) The committees' focus ranges from APT, mentoring, or executive, with varying degrees of involvement by a dean, assistant dean or department chair. UIC, UML, Rutgers, and LSU use forms or questionnaires to aid in creating compatible matches. The ideal form provides data that programs can use for linking mentors and mentees with similar research interests, education backgrounds, work duties, and special needs.

Not all matches work, and, as discussed above, mentoring programs must offer a means to terminate or reassign a mentoring relationship. The mentor or mentee can request reassignment. This sort of "exit clause" exists at seven of the institutions examined here and is usually coordinated in confidence by a party external to the relationship. UML stipulates that the relationship may be terminated once the mentee has achieved tenure, if not earlier. At Rutgers, the relationship can end after a one-year evaluative cycle. Ideally, one committed mentor guides a mentee throughout the early stages of the mentee's career until promotion and tenure are attained. The commitment can last as long as nine years at UML. A longterm professional relationship such as this can also benefit from tracking and evaluative mechanisms.

\section{Tracking and Evaluation Mechanisms}

Some form of tracking mechanism for mentoring programs is used at six of the ten institutions examined. Three - UIC, UML, and Oklahoma State - rely on personal contacts with the participants by those administering the program. This informal contact minimizes paperwork and adds a human element to tracking and monitoring the relationships. LSU encourages participants to submit periodic reports. SUNY-Albany and Rutgers track their mentoring relationships with the same forms they use for evaluating the mentoring program. Each institution incorporates different evaluative tools for its programs, whether they are called a questionnaire, a form, or a survey. Some programs, such as UIC and UML, are still developing evaluative mechanisms. Wisconsin relies on personal contacts from its program coordinator for evaluation and has also evaluated the entire mentoring program.

Regardless of how a program is evaluated or tracked, the mentor should not be held accountable for a mentee's advancement. The tracking documents can indicate that the two met frequently, and the evaluative documents can indicate the mentor's impression of the mentee's progress, but the mentee may still fail. The mentor can only offer guidance; he or she cannot realize the criteria necessary for promotion and tenure for the mentee. That responsibility ultimately lies with the mentee. Such expectations and parameters - to say nothing of the tracking or evaluative mechanisms - are best conveyed via a thorough training curriculum in support of the mentoring program.

\section{Training for a Successful Mentoring Program}

The skills necessary for mentoring do not come naturally to everyone. The boundaries and expectations that enable dynamic mentoring are not always clear for those new to such a relationship. Mentoring programs also frequently require reporting or matching mechanisms that may not prove intuitive. Training can address these challenges.

Minimally, training addressing local protocols for a mentoring program is needed. Mentoring planners at UML have realized that forms and their submission processes are never as intuitive as hoped, and evaluative documentation requires explanation. Another key concern at UML is that criteria for APT may have changed since the mentor achieved tenure. Periodic re-training can help mentors stay well versed in an institution's current APT criteria. What is needed from each evaluation will vary by institution. It also helps for mentors and mentees to have the procedures for terminating a relationship 
explained in person. This discussion is a delicate matter that should not be left to Web pages and handbooks where misinterpretation is possible. Such training suggestions only get into the logistics of mentoring; how to be a mentor requires a different kind of training (Byrne).

The skills required for effective mentoring can be elusive and not predictably quantified from person to person. So much of what makes an effective mentor are the unique personal qualities adjusted to suit a particular mentoring relationship. Mentors or potential mentors should look to multiple opportunities for training. For example, the Association of College and Research Libraries (ACRL) has offered an excellent interactive Web-cast on mentoring librarians, although it is not in ACRL's current catalog. Similarly, mentors can attend mentoring-related sessions at professional conferences and meet mentors at other institutions to compare experiences. Literature on the subject is plentiful, and a mentoring coordinator or committee can easily post a mentoring-related bibliography. Some institutions offer home-based training programs addressing mentoring faculty and related skills such as providing feedback. Yet, as with most professional endeavors, adhering to established best practices is also a recommended course to pursue.

\section{BEST PRACTICES OF MENTORING FOR LIBRARIANS WITH FACULTY STATUS}

Based on the programs examined earlier and the recommendations outlined by Wittkopf, the authors have identified the following best practices:

1. The mentoring program for faculty librarians mirrors the campus policy and practice for teaching faculty. Typically, the final approval for tenure comes from outside the library system, at the administrative level for the institution. The faculty librarian attempting to achieve tenure must do so in an environment consistent with his or her teaching and research faculty peers. As the mentoring program supports the pursuit of tenure, it must help to create that environment in the library system.

2. The benefits of the mentoring program for both mentor and mentee are enunciated. It is reasonable to expect some resistance to a new program or even confusion surrounding its value. The clearer the benefits are, and the more they are marketed, the more likely it is that resistance to the program is replaced by enthusiasm.

3. Responsibilities, characteristics, and expectations of mentees and mentors are clearly defined. These factors are commonly communicated through two vehicles generated by institutions: training and literature, either online or in print. It is easy to over-explain a program, but just as easy to produce vague guidelines. Balance is necessary.

4. The eligibility criteria to become a mentor are clear. The needs for mentoring vary among all of the institutions examined. With such variance come differing qualifications for the mentor. Each institution must define what criteria are required to mentor. Once established, the institution should adhere to that definition so the program can progress consistently and coherently.

5. Senior faculty members are informed about mentoring and are supported in becoming and being mentors. The careers of tenured faculty are enhanced by the opportunity to serve in this timetested role. It is more beneficial to mentees when the senior faculty members have navigated the tenure process or served on tenure review committees at the institution.

6. It is clear whether the program is voluntary or required. As stated earlier, each program will support different needs for library faculty. Thus, it is vital that the program's basic elements of are clearly defined. Furthermore, the consequences are real for the newer faculty member who mistakenly operates outside the APT processes of the institution. The status of the mentoring program must be clear, promoted, and consistently applied. 
7. There is a step-by-step process for matching and training potential mentees and mentors. Clarity will contribute to the mentoring program's success. The process should be efficient and not bogged down in excessive procedures and paperwork.

8. The individuals or groups coordinating the program are identified, and responsibilities and authority are defined. Those participating in the program must know whom to turn to for support or submission of evaluative documentation.

9. Options are identified for the mentor-mentee relationship to end, should interests or needs shift. It is also useful to define when the relationship can end naturally, such as in the attainment of tenure.

10. An ongoing process for evaluating the program is outlined, as well as a process for changing and improving the program as evaluations indicate. The field of librarianship evolves perpetually. APT requirements are also frequently adjusted to match the trends in higher education (Field, 2001). Therefore, periodic evaluation of the mentoring programs can enable them to stay relevant and useful to the library system.

These recommended best practices are a good starting point for instituting a program. They address the basic mechanics, attributes, and benefits surrounding mentoring. Additional best practices may result from comprehensive research into the impact of mentoring on promotion and retention.

\section{FUTURE RESEARCH DIRECTIONS}

The implications for future research in mentoring are broad. It seems clear that mentoring is beneficial to both the mentor and the mentee. There are opportunities for future research endeavors that can help to close the gaps that exist in mentoring programs and the mentoring relationships. Such research might center on recruitment and retention of a diverse workforce, identification and isolation of specific skills that establish and enhance trusting relationships, and increasing the probability of viable matches and successful outcomes. Future research may also include expanded use of e-mentoring for faculty with disabilities. E-mentoring has been used for students with disabilities and is frequently utilized for electronic forums (Burgstahler and Crawford, 2007). There is also growing use of mentoring networks that some describe as “... a vital contribution to a successful academic career” (Sorcinelli and Jung, 2007, p.58). Given the complex nature of mentoring relationships, it would be a worthwhile to undertake research on isolating the success factors.

The mentoring relationship succeeds or fails for a number of reasons. Moberg's research involved two studies of whether those who mentor are more practically wise than those who do not. The studies provided no evidence of significant differences in the levels of practicality among those who mentored and those who did not. However, the studies did suggest that mentors had more political skills than those who were not mentors. (Moberg, 2008). In their paper titled "Intentions to Initiate Mentoring Relationships: Understanding the Impact of Race, Proactivity, Feelings of Deprivation, and Relationship Roles” Hu, Thomas and Lance discussed how exploring certain factors in the initial phase of the mentoring relationship might affect the relationship's development (2008). They state, "Researchers have failed to explore factors that promote or hinder successful mentorship initiation, specifically the role that a person’s characteristics play in the mentorship initiation” (p. 728).

One interesting approach would be to form a research team of experienced and neophyte researchers to examine some aspect of mentoring, from an academic library standpoint. Such a team would be able to conduct a dual activity: researching an aspect of mentoring and examining the relationship activity within the team. There are plentiful opportunities and fertile ground for continued research on mentoring. The current research recognizes that the complexities of human nature and the 
mechanics of the mentoring process come together in fascinating ways and, if successful, create a finely tuned interrelationship of both professional and personal growth. Filling in the gaps of specifically how and why this happens suggests that there is much more work to do.

Perhaps the most obvious area for research is the systematic, longitudinal collection of data to support mentoring programs' effects on achievement of promotion and tenure, as well as on retention of library faculty without tenure. It has been acknowledged that these factors will not be easy to isolate, but the efforts need to be made nevertheless.

\section{CONCLUSION}

Research and writing about mentoring are done in an environment rich with previous research and writing and can renew individual commitment to meeting the challenges and taking advantage of the opportunities to mentor and be mentored. Especially in an academic environment where librarians have faculty status, and where mentoring is not or should not be optional or voluntary, the stimulus to renewed institutional commitment to the principles and practices of mentoring is needed. The themes in this chapter serve to encourage as well as inform. Given the rapidly changing landscapes of information delivery and library service and operations, librarians as information professionals must keep current, and mentoring or being mentored is one excellent tool in this effort. 


\section{REFERENCES}

Burgstahler, S., \& Crawford, L. (2007). Managing an e-mentoring community to support students with disabilities: A case study. Association for the Advancement of Computing in Education Journal, 15(2), 97-114.

Blessinger, K. (2009). E-mail sent to Vincent J. Novara, 24 April 2009.

Bowen, L.G., \& Roberts, P.J. (1993). Exhibits: Illegitimate children of academic libraries? College \& Research Libraries, 54, 407-415.

Byrne, D. (2003). Mentoring. Library \& Information Update, 2 (4), 38-39.

Carter, T., Griffey, J., \& Prince, B. (2006). Developing an orientation and mentoring program. Tennessee Libraries, 56 (2), 1-15.

Eastern Illinois University (2009). Honors Faculty Mentoring Partnership. Retrieved May 1, 2009, from htttp://www.eiu.edu/ honprog/hf_faculty_mentoring.php

Farmer, D., Stockham, M., \& Trussell, A. (2009). Revitalizing a mentoring program for academic libraries. College \& Research Libraries, 70 (1), 8-24.

Field, J. (2001). Mentoring: a natural act for information professionals? New Library World, 102 (7/8), 269-273.

Hu, C., Thomas, K., \& Lance, C. (2008). Intentions to initiate mentoring relationships: Understanding the impact of race, proactivity, feelings of deprivation, and relationship roles. Journal of Social Psychology, 148 (6), 727-744. Retrieved February 13, 2009, from http://www.ebscohost.com.

Judason, M. Mentoring new colleagues: A practical model from the University of Wisconsin-Madison. Retrieved February 12, 2009, from http://www.lib.niu.edu/1997/il970123.html.

Kuyper-Rushing, L. (2001). A formal mentoring program in a university library: components of a successful experiment. Journal of Academic Librarianship, 27 (6), 440-6.

Mitchell, W.B. \& Morton, B. (1992). On becoming faculty librarians: Acculturation problems and remedies. College \& Research Libraries, 53, 379-392.

Moberg, D. (2008) Mentoring and practical wisdom: Are Mentors wiser or just more politically skilled? Journal of Business Ethics, 83 (4), 835-843. Retrieved February 13, 2009, from http://www.springerlink.com.

Munde, G. (2000). Beyond Mentoring: Toward the rejuvenation of academic libraries. Journal of Academic Librarianship, 26 (3), 171-175.

The Ohio State University Libraries (2008). Guidelines for the Faculty Mentoring Program. Retrieved February 12, 2009, from http://library.osu.edu/sites/staff/apt/mentoring.html.

Popper, A.N. (2007). Mentoring of junior faculty: A guide for faculty mentors (and mentees) in the college of chemical and life sciences. Retrieved April 15, 2009, from

http://www.faculty.umd.edu/Mentoring/MentoringGuide.pdf. . 
Rutgers University Libraries (2006). Mentoring Program Report. Retrieved February 12, 2009, from http://www.libraries.rutgers.edu/rul/staff/lib_fac/pdfs/mentoring_program_report.pdf.

Sorcinelli, M.D. \& Jung, Yun (2007). From mentor to mentoring networks: Mentoring in the new academy. Change, 39(6), 58-61.

Sorcinelli, M.D. (2000). Principles of good practice: Supporting early-career faculty. Washington, DC: American Association for Higher Education.

Syma, C. and C. Henry (2009). Sharing program: the big-boy boomeroo of mentoring. C\&RL News, 70(3) 178-180.

Troy, S. (2009). E-mail sent to Vincent J. Novara, April 24, 2009.

University of Illinois at Chicago Library (2005). Faculty mentoring program: Guidelines for UIC library mentoring program. Retrieved February 12, 2009, from http://www.uic.edu/depts/lib/about/facexec/facmentor/guidelines.shtml.

University of Iowa. (2008.) Mentoring at the University of Iowa. Retrieved April 10, 2009, from http://provost.uiowa.edu/mentoring.

University of Maryland Libraries (2009.) Library faculty mentoring program guidelines. Retrieved February 12, 2009, from http://lib.umd.edu/PASD/LPO/mentgl.doc.

Washington State University (2009). Faculty mentoring guidelines. Retrieved April 10, 2009, from http://provost.wsu.edu/faculty_mentoring/guidelines.html.

Wittkopf, B. (1998). Mentoring programs in ARL libraries. (ARL SPEC Kit 239) Washington, DC: Association of Research Libraries.

Zellers, D.F., V.M. Howard, and M.A. Barcic (2008). Faculty mentoring programs: Reenvisioning rather than reinventing the wheel. Review of Educational Research, 78, 552-588. 
ADDITIONAL READING (and used as background sources for this chapter)

American LibraryAssociation. (2007). Mentoring the untenured librarian. American Library Association, June 18, 2007. Retrieved May 5, 2009, from http://www.ala.org/ala/mgrps/divs/acrl/publications/crlnews/2005/nov/mentoring.cfm.

Bell, C.R. (2002). Managers as mentors: Building partnerships for learning. 2nd ed. San Francisco: Berrett-Koehler Publishers.

Demirhan, A. (2005). Developing leadership through mentoring. Florida Libraries, 48 (2), 15-16.

DeZelar-Tiedman, C., Camden, B., Uhl, R. (2006). Growing our own: Mentoring the next generation of catalog librarians. Cataloging \& Classification Quarterly, 43 (2), 19-35.

Loracco, D.J. \& Bruns, D. (2006). Practitioner to professor: An examination of second career academic entry into academia. Education, 126 (4), 626-639.

Morano, M. (1999). Challenges encountered by new advisers: Honest answers, practical solutions. The Mentor: An Academic Advising Journal, 1 (1). Retrieved February 13, 2009, from http://www.psu.edu/dus/mentor/volume01.htm.

Osif, B. (2006). Mentoring: Part I. Library Administration and Management, 20 (4), 209-213.

Osif, B. (2007). Mentoring: Part II. Library Administration and Management, 21 (1), 44-48.

Oud, J. (2008). Adjusting to the workplace: Transitions faced by new academic librarians. College \& Research Libraries, 69 (3), 252-266.

Savage, H. E., Karp, R. S., \& Logue, R. (2004). Faculty mentorship at colleges and universities. College Teaching, 52 (1), 21-24.

Sorcinelli, M.D. (1994). Effective approaches to new faculty development. Journal of Counseling and Development, 72 (5), 474-479.

Weiler, R.L., D’Enbeau, S., Buzzanell, P.M. (2008) Handbook of mentoring at work: theory, research, and practice. Management Communication Quarterly, 21 (3), 413-417.

Williams, A. (2008). A helping hand for young faculty members. Chronicle of Higher Education, 55 (3), A10. 